\title{
Phenolic composition and antioxidant properties of Pleurotus ostreatus and Pleurotus eryngii enriched with selenium and zinc
}

\author{
Monika Gąsecka $^{1} \cdot$ Mirosław Mleczek $^{1} \cdot$ Marek Siwulski $^{2} \cdot$ Przemysław Niedzielski $^{3}$
}

Received: 9 July 2015 / Revised: 14 October 2015 / Accepted: 24 October 2015 / Published online: 17 November 2015

(C) The Author(s) 2015. This article is published with open access at Springerlink.com

\begin{abstract}
The aim of the study was to investigate the antioxidant properties, phenolic and flavonoid contents and composition and content of ascorbic acid in Pleurotus ostreatus and Pleurotus eryngii enriched simultaneously with selenium (Se) and zinc ( $\mathrm{Zn})$. Non-enriched mushrooms contained $\mathrm{Se}$ and $\mathrm{Zn}$ at the level as in the most popular mushrooms. The total phenolic content (TPC) for non-enriched $P$. ostreatus and $P$. eryngii was $9.64 \pm 0.33$ and $7.91 \pm 1.02 \mathrm{mg} / \mathrm{g}$ of extract, the total flavonoid content was $2.11 \pm 0.19$ and $1.26 \pm 0.17 \mathrm{mg} / \mathrm{g}$ of extract, and ascorbic acid content ranged from $10.28 \pm 0.39$ to $16.64 \pm 0.47 \mathrm{mg} / 100 \mathrm{~g}$ DW, respectively. Methanolic extracts contained 4-hydroxybenzoic, ferulic, $p$-coumaric, protocatechuic, $t$-cinnamic and vanillic acids and naringenin. In methanolic extract of $P$. eryngii, 2,5-dihydroxybenzoic acid was also quantified. The correlation between the TPC and antioxidant activity in mushroom was confirmed. Additionally, the correlations between $\mathrm{Zn}$ and Se concentration in fruiting bodies and $\mathrm{EC}_{50}$ value and phenolic compounds were confirmed. Our results with simultaneous supplementation with $\mathrm{Zn}$ and Se provide the opportunity to increase the content of the elements in fruiting bodies and to improve antioxidant properties and antioxidant contents in enriched mushrooms. Additionally, the obtained results demonstrated that simultaneous
\end{abstract}

Monika Gąsecka

buba@up.poznan.pl

1 Department of Chemistry, Poznań University of Life Sciences, Poznan, Poland

2 Department of Vegetable Crops, Poznań University of Life Sciences, Poznan, Poland

3 Faculty of Chemistry, Adam Mickiewicz University in Poznań, Poznan, Poland enrichment with micronutrients with a contrary effect on antioxidant properties can activate synthesis of phenolic compounds and ascorbic acid. The investigation is the first study evaluating the effect of addition of two elements to the substrate at the same time on antioxidant properties of mushrooms.

Keywords Phenolic and flavonoid compounds .

Selenium · Zinc $\cdot$ Ascorbic acid - Antioxidant properties . Pleurotus

\section{Introduction}

Mushrooms are a valuable component of the human diet due to their nutritional and medicinal value. They are a source of compounds responsible for antimicrobial, antioxidant, antitumor and antiinflammatory properties [1-8]. The consumption of food rich in antioxidants plays a protective role for human health, because of the reduction in oxidative damage resulting in enhanced generation of free radicals $[9,10]$. Free radicals are unstable and highly reactive, due to having unpaired electrons; they are responsible for oxidative stress, and in consequence, they cause DNA damage, carcinogenesis, oxidation of biomolecules and cellular degradation related to aging, etc. [11-14].

Phenolic compounds are mushroom antioxidants which are strong radical scavengers and free radical inhibitors and phytonutrients $[15,16]$. The common feature of this very diverse group of metabolites including flavonoids, phenolic acids, stilbenes, lignin, tannins is possessing in the structure one or more aromatic rings with hydroxyl groups [15, 17].

Ascorbic acid is the enolic form of an $\alpha$-ketolactone (2,3-didehydr L-threo-hexano-1,4-lactone) and is the 
functional form of vitamin C [18], which has a protective role in human health and acts as an electron donor for human enzymes (reducing agent or antioxidant) [19].

Selenium (Se) and zinc ( $\mathrm{Zn})$ are trace elements important for human health [20]. Se is a component of antioxidant enzymes via amino acid (selenocysteine, selenomethionine) and proteins [21-23]. $\mathrm{Zn}$ is a component of enzymes participating in the synthesis and degradation of different biomolecules including lipids, proteins, carbohydrates and nucleic acids as well as in the metabolism of other micronutrients [19]. The antioxidant properties of $\mathrm{Zn}$ in detoxification of reactive oxygen species (ROS) such as $\mathrm{OH}, \mathrm{O}_{2}^{-}$and $\mathrm{H}_{2} \mathrm{O}_{2}$ were confirmed in $\mathrm{Zn}$-metallothionein and in the enzyme $\mathrm{Cu}-\mathrm{Zn}$ superoxide dismutase $[12,24]$.

The deficiency of micronutrient is associated with health disturbances, and thus, different cultivation practices have been successfully implemented to increase the nutritional value of mushrooms [21, 25, 26]. It was also documented that enrichment with micronutrients had an impact on antioxidant activities and phenolic content [26-28]. In publications mentioned, the impact of a single element on antioxidants was determined. The present study is a continuation of our experiment on mushroom enrichment [28].

The main objective of the study was to determine phenolic, flavonoid and ascorbic acid contents and antioxidant activity of methanolic extracts from $P$. ostreatus and $P$. eryngii enriched with Se and $\mathrm{Zn}$. Additionally, the individual profile of phenolics in extracts of the mushrooms was determined. To our knowledge, it is the first study on the impact of simultaneous enrichment of substrates with different micronutrients on antioxidants in edible mushrooms.

\section{Materials and methods}

\section{Mushroom material}

Experiments were designed following Gąsecka et al. [28] with some modifications. Wheat straw cut into chaff $4-5 \mathrm{~cm}$ long was placed in polypropylene bags with $60 \%$ moisture content. After pasteurization at $60{ }^{\circ} \mathrm{C}$ for $24 \mathrm{~h}$, it was used as substrate for the $P$. ostreatus experiments. Sodium selenite $\left[\mathrm{Na}_{2} \mathrm{SeO}_{3}\right.$ (IV)], sodium selenate $\left[\mathrm{Na}_{2} \mathrm{SeO}_{4}(\mathrm{VI})\right]$ and zinc nitrate hexahydrate $\left[\mathrm{Zn}\left(\mathrm{NO}_{3}\right)_{2} \times 6 \mathrm{H}_{2} \mathrm{O}\right]$ were dissolved in an amount of sterile water sufficient to obtain their appropriate concentration in the substrate. After addition of the salt solution, the substrate reached the moisture content of $70 \%$. The final concentration of the salts was $1.5 \mathrm{mM}$ (each in five replicates). The substrate was mixed with $3 \%$ of spawn (wheat grain) using a POLYMIX PX-SR 90 D stirrer (Kinematica AG, Littau-Luzern, Switzerland). Then, $1 \mathrm{~kg}$ of the substrate was placed in bags of perforated foil and incubated at $25{ }^{\circ} \mathrm{C}$ and $85-90 \%$ air relative humidity (RH). Once the bags were totally colonized, they were placed in the cultivation chamber $\left(15-16{ }^{\circ} \mathrm{C}\right.$ and $85-90 \% \mathrm{RH})$ and illuminated with fluorescent light of 500 lux intensity $10 \mathrm{~h}$ a day. The growth facility was aerated to maintain $\mathrm{CO}_{2}$ concentration below $1000 \mathrm{ppm}$.

The substrate for P. eryngii was prepared as a mixture of beech sawdust and flax shives (3:1 vol.) supplemented with wheat bran in the amount of $20 \%$, corn flour $5 \%$ and gypsum $1 \%$ in relation to the substrate dry matter. Substrate moisture was adjusted to $45 \%$ using distilled water, and then, it was bagged in polypropylene bags and sterilized at $121^{\circ} \mathrm{C}$ for $1 \mathrm{~h}$ and finally cooled down to $25^{\circ} \mathrm{C}$. Se and $\mathrm{Zn}$ salt solutions were prepared as described above and were added to the substrate to obtain the appropriate concentration (1.5 mM each in five replicates) in the substrate with $60 \%$ moisture. Then, the substrate with Se and $\mathrm{Zn}$ addition was mixed with spawn (wheat grain) of the mushroom ( $5 \%$ of substrate weight). A total of $350 \mathrm{~g}$ of the substrate was placed in polypropylene bottles of $1 \mathrm{dm}^{3}$ volume and closed with a cover with a filter. The incubation was conducted at the temperature of $25{ }^{\circ} \mathrm{C}$ and $80-85 \%$ RH until the substrate became completely colonized with mycelium. Next, the bottles without covers were placed in the cultivation chamber (85-90\% RH and $14 \pm 1{ }^{\circ} \mathrm{C}$ ) and lit with fluorescent light of $500 \mathrm{~lx}$ intensity $12 \mathrm{~h}$ a day. The growth facility was aerated in such a way as to maintain $\mathrm{CO}_{2}$ concentration below $1000 \mathrm{ppm}$.

Fruiting bodies of $P$. ostreatus and $P$. eryngii were collected after maturation, dried in an electric oven (SLW 53 STD, Pol-Eko, Wodzisław Śląski, Poland) at $50 \pm 2{ }^{\circ} \mathrm{C}$ for $48 \mathrm{~h}$ and ground for $0.5 \mathrm{~min}$ in a Cutting Boll Mill 200 (Retsch GmbH, Haan, Germany). For the extraction procedure, five representative powdered samples were used.

\section{Chemicals}

2,2-Diphenyl-1-picrylhydrazyl (DPPH), $\quad \mathrm{Na}_{2} \mathrm{SeO}_{3}$, $\mathrm{Na}_{2} \mathrm{SeO}_{4}, \mathrm{Zn}\left(\mathrm{NO}_{3}\right)_{2} \times 6 \mathrm{H}_{2} \mathrm{O}, \mathrm{NaNO}_{2}, \mathrm{AlCl}_{3}, \mathrm{Na}_{2} \mathrm{CO}_{3}$, $\mathrm{NaOH}, \mathrm{HNO}_{3}, \mathrm{H}_{2} \mathrm{O}_{2}$, Folin-Ciocalteu phenol reagent, formic, gallic, protocatechuic, benzoic, 2,5-dihydroxybenzoic, 4-hydroxybenzoic, caffeic, chlorogenic, vanillic, salicylic, syringic, $p$-coumaric, ferulic, sinapic and $t$-cinnamic acids, rutin, catechin, kaempferol, quercetin, vitexin, luteolin, naringenin, apigenin and methanol were purchased from Sigma-Aldrich (St. Louis, MO, USA). Se standard solution was purchased from Merck (Darmstadt, Germany).

\section{Se determination}

Mineralization of dry fruiting bodies of the mushrooms $(1.0000 \pm 0.0001 \mathrm{~g})$ was performed using $8 \mathrm{~mL}$ of $65 \%$ $\mathrm{HNO}_{3}$ and $1 \mathrm{~mL}$ of $30 \% \mathrm{H}_{2} \mathrm{O}_{2}$ with a CEM Mars 5 Xpress microwave mineralization system (CEM Corp., Matthews, 
NC, USA) according to the following microwave threestage program: first stage - power $400 \mathrm{~W}$, time $2 \mathrm{~min}$, temperature $100{ }^{\circ} \mathrm{C}$; second stage-power $600 \mathrm{~W}$, time $5 \mathrm{~min}$, temperature $160{ }^{\circ} \mathrm{C}$; the third stage-power $1000 \mathrm{~W}$, time $10 \mathrm{~min}$, temperature $200{ }^{\circ} \mathrm{C}$. Solutions after mineralization were filtered through 45-mm filters (Qualitative Filter Papers, Whatman, Grade 595: 4-7 $\mu \mathrm{m}$, UK). Then, the whole contents were made up to a final volume of $50.0 \mathrm{~mL}$ with deionized water (Milli-Q Advantage A10 Water Purification Systems, Merck Millipore, Darmstadt, Germany). Total Se concentration in samples was determined by electrothermal atomic absorption spectrometry (ETAAS) using an Agilent Technologies AA Duo-AA280FS/AA280Z spectrometer (Agilent Technologies, Mulgrave, Victoria, Australia). Pyrolytic graphite tubes and a Se hollow cathode lamp (wavelength $196.0 \mathrm{~nm}$, slit $1.0 \mathrm{~nm}$, lamp current $10 \mathrm{~mA}$ ) were used. The optimized temperature program was used: drying step at $85-120{ }^{\circ} \mathrm{C}$ for $55 \mathrm{~s}$; ashing step at $1000 \mathrm{C}$ for $8 \mathrm{~s}$; atomization at $2600{ }^{\circ} \mathrm{C}$. As a chemical modifier, palladium solution was used $(10 \mu \mathrm{L}$ of $500 \mathrm{mg} / \mathrm{L}$ for $20 \mu \mathrm{L}$ of sample). For the preparation of the calibration curve, the commercial Se standard in $1 \mathrm{~g} / \mathrm{L}$ concentration was used as the appropriate diluted standard. The linearity of the calibration curve was 0.9996 ; the detection limit for liquid samples was $0.0007 \mathrm{mg} / \mathrm{L}$. The range of the calibration curve was from the detection limit to $0.080 \mathrm{mg} / \mathrm{L}$. Precision measured as relative standard deviation was at the level of 3-5\%. The uncertainty of the whole analytical procedure (sample preparation and analysis) did not exceed $20 \%$. Due to the lack of reference material, the traceability was determined in a standard addition procedure. The obtained recovery values were in the range 96.7-104.1\%. The determination level for the solid samples was $0.1 \mathrm{mg} /$ $\operatorname{kg}[29,30]$.

For $\mathrm{Zn}$ determination, flame (air-acetylene) atomic absorption spectrometry was used. The following determination conditions were used: a stoichiometric flame $(2.0 \mathrm{~L} /$ min acetylene and $13.5 \mathrm{~L} / \mathrm{min}$ air), using hollow cathode lamps (HCL) and background correction with a deuterium lamp. The spectral conditions were: wavelength $213.9 \mathrm{~nm}$ and slit $1.0 \mathrm{~nm}$. A Zn hollow cathode lamp (HCL) was used with the current $5 \mathrm{~mA}$. The determination limit was $1.0 \mathrm{mg} /$ $\mathrm{kg}$. The uncertainty (understood as a parameter characterizing the dispersion of the values attributed to a measured parameter; the main component of uncertainty was precision) of the entire analytical process (sample preparation and spectrometric measurements) did not exceed $15 \%$. Due to the lack of reference material, the traceability was determined in a standard addition procedure. The obtained recovery values were in the range $94.3-103.8 \%$.

\section{Extraction}

Ten grams of the powdered mushroom samples or substrates was mixed with $100 \mathrm{~mL}$ of $80 \%$ methanol. Samples were sonicated, shaken in an Ika KS 260 shaker (IKA-Werke GmbH \& Co. Kg, Staufen, Germany) for $8 \mathrm{~h}$, centrifuged at $3000 \mathrm{rpm}$ with a Universal $320 \mathrm{R}$ centrifuge (Hettich, Tuttlingen, Germany) and then filtered through Whatman No. 4 paper (UK). The extraction was repeated twice, and both supernatants were mixed and evaporated at $40{ }^{\circ} \mathrm{C}$ to dryness using Büchi Rotavapor R-205 (Flawil, Switzerland). The obtained residues were weighed and stored at $-12{ }^{\circ} \mathrm{C}$ until the analyses. For further analysis, the extract was redissolved in $1 \mathrm{~mL}$ of $80 \%$ of methanol [28].

\section{Total phenolic and ascorbic acid contents}

The total phenolic content (TPC) was determined with the Folin-Ciocalteu reagent [31]. To improve the specificity for TPC determination with the Folin-Ciocalteu method, the modification based on simultaneous quantification of ascorbic acid content (AAC) was introduced according to Sánchez-Rangel et al. [32] and Isabelle et al. [33]. Methanolic extract was mixed with diluted Folin-Ciocalteu phenol reagent (1:1 with water, v:v), and after $3 \mathrm{~min}$, the absorbance at $\lambda=765 \mathrm{~nm}$ was measured with a Varian Cary 300 Bio UV-Visible scanning spectrophotometer. Afterward, $20 \% \mathrm{Na}_{2} \mathrm{CO}_{2}$ was added and the samples were kept in the dark for $2 \mathrm{~h}$ at room temperature. The absorbance at $\lambda=765 \mathrm{~nm}$ was measured. The corrected TPC was obtained by subtracting AA reducing activity from the TPC absorbance values. The results of TPC were expressed in $\mathrm{mg}$ of chlorogenic acid (CHA) equivalents per $\mathrm{g}$ of dried extract (mg CHA/g). The results of AAC were expressed as $\mathrm{mg}$ per $100 \mathrm{~g}$ of dried weight of mushroom. The results of AA reducing activity were expressed as AAC multiplied by 1.43 [32].

\section{Total flavonoid content}

Total flavonoid content (TFC) was measured according to Choi et al. [34], and also Lin and Tang [35] with some modifications. A total of $250 \mu \mathrm{L}$ of methanolic extract, $1.25 \mathrm{~mL}$ of distilled water and $75 \mu \mathrm{L}$ of $5 \% \mathrm{NaNO}_{2}$ were mixed together. After $6 \mathrm{~min}, 150 \mu \mathrm{L}$ of $10 \% \mathrm{AlCl}_{3}$ was added. After the next $6 \mathrm{~min}, 4 \mathrm{~mL}$ of $4 \% \mathrm{NaOH}$ and $2.5 \mathrm{~mL}$ of deionized water were added. The absorbance was measured at $510 \mathrm{~nm}$, and TFC was expressed as mg rutin equivalents per $\mathrm{g}$ of dried extract. 


\section{Chromatographic analysis}

Chromatographic analysis was performed with a Waters ACQUITY UPLC H-Class System (Waters Corp., Milford, MA, USA), consisting of a quaternary pump solvent management system, an online degasser and an autosampler. An a Acquity UPLC HSS T3 $\mathrm{C}_{18}$ column $(150 \mathrm{~mm} \times 2.1 \mathrm{~mm}$, particle size $1.8 \mu \mathrm{m}$ ) (Waters, Ireland) was applied for all analyses. The raw data were acquired and processed with Empower software. Before injection, the extracts were filtered through a $0.22 \mathrm{~mm}$ syringe filter. The mobile phase was composed of A (water, containing $0.10 \%$ formic acid) and B (acetonitrile, containing $0.10 \%$ formic acid) with a gradient program as follows: flow $0.4 \mathrm{~mL} / \mathrm{min}-5 \% \mathrm{~B}$ (2 min), 5-16\% B (5 min), $16 \%$ B (3 min), 16-20\% B (7 min), 20-28\% B (11 min) flow $0.45 \mathrm{~mL} / \mathrm{min}-28 \%$ (1 min), 28-60\% B (3 min) flow $5.0 \mathrm{~mL} / \mathrm{min}-60-95 \% \mathrm{~B}$ (1 min), $65 \%$ B (1 min), 95-5 \% B (0.1 min) flow $0.4 \mathrm{~mL} /$ min $5 \% \mathrm{~B}(1.9 \mathrm{~min})$. The detection was carried out in a photodiode array detector (PDA) e $\lambda$ (Waters Corporation, Milford, MA, USA), and measurements of phenolic compound concentrations were performed using an external standard at wavelengths $\lambda=320 \mathrm{~nm}$ (chlorogenic acid, caffeic acid, $p$-coumaric acid, ferulic acid, salicylic acid, sinapic acid, vitexin, rutin, quercetin, luteolin, apigenin, kaempferol), $\lambda=280 \mathrm{~nm}$ (gallic acid, protocatechuic acid, 4-hydroxybenzoic acid, vanillin, syringic acid, vanillic acid, $t$-cinnamic acid, naringenin) and $\lambda=230 \mathrm{~nm}$ (catechin, benzoic acid). Compounds were identified based on a comparison of retention times of the examined peak with that of the standard and by adding a specific amount of the standard to the tested sample and repeated analyses. The limit of detection was $1 \mathrm{mg} / \mathrm{kg}$ [36].

\section{DPPH radical scavenging assay}

The radical scavenging assay was prepared as previously described [28]. One milliliter of methanolic extracts at a concentration between 2 and $20 \mathrm{mg} / \mathrm{mL}$ was mixed with $2.7 \mathrm{~mL}$ of $6 \mu \mathrm{mol} / \mathrm{L}$ methanolic solution of 2,2-diphenyl1-picrylhydrazyl (DPPH) radicals. The mixture was shaken and kept in the dark at room temperature for $60 \mathrm{~min}$. The reduction of the DPPH radical was measured by monitoring the decrease in absorbance at $517 \mathrm{~nm}$. The DPPH radical scavenging activity was calculated according to the formula [37]:

Inhibition $(\%)=\left(A-A_{C}\right) / A \times 100$.

where $A$ absorbance of control (DPPH solution without extract), $A_{C}$ absorbance of methanolic extract of mushroom.

The scavenging activity expressed as $\mathrm{EC}_{50}$ represented the concentration of a sample having $50 \%$ of the DPPH radical scavenging effect and was estimated graphically.

\section{Statistical analysis}

All analyses were prepared in five replicates, and the results were expressed as mean value \pm SD. The data were processed using Microsoft Excel 2010. Statistical analysis was done using STATISTICA 10 (StatSoft, USA) statistical software with one-way ANOVA followed by post hoc Tukey's test (the results marked with identical letters in rows exhibit no differences at the significance level $\alpha=0.05$ ). The Pearson correlation coefficients for selected pairs of parameters were also estimated.

\section{Results and discussion}

\section{Se and $\mathrm{Zn}$ enrichment and their content}

The contents of $\mathrm{Se}$ and $\mathrm{Zn}$ in substrates and in fruiting bodies of Pleurotus species are shown in Table 1 . The $\mathrm{Se}$ and $\mathrm{Zn}$ concentration in substrates significantly increased after supplementation. The Se concentration in non-enriched P. ostreatus (control) was $2.73 \pm 0.26 \mathrm{mg} /$
Table 1 Se and $\mathrm{Zn}$ concentration in substrates and in P. ostreatus and P. eryngii fruiting bodies $(\mathrm{mg} / \mathrm{kg} \mathrm{DW})$

\begin{tabular}{lcccc}
\hline & SPoc & SPoSeZn & Poc & PoSeZn \\
\hline Se & $5.12 \pm 0.76^{\mathrm{b}}$ & $54.87 \pm 0.76^{\mathrm{a}}$ & $2.73 \pm 0.26^{\mathrm{b}}$ & $109.74 \pm 11.06^{\mathrm{a}}$ \\
$\mathrm{Zn}$ & $14.72 \pm 0.51^{\mathrm{b}}$ & $45.67^{\mathrm{a}} \pm 1.07$ & $26.00 \pm 0.82^{\mathrm{b}}$ & $32.93 \pm 0.99^{\mathrm{a}}$ \\
\hline & $\mathrm{SPec}$ & SPeSeZn & Pec & PeSeZn \\
\hline $\mathrm{Se}$ & $7.32 \pm 0.93^{\mathrm{b}}$ & $59.98 \pm 1.33^{\mathrm{a}}$ & $2.07 \pm 0.68^{\mathrm{b}}$ & $54.39 \pm 0.79^{\mathrm{a}}$ \\
$\mathrm{Zn}$ & $22.45 \pm 1.03^{\mathrm{b}}$ & $56.23 \pm 0.47^{\mathrm{a}}$ & $22.98 \pm 0.84^{\mathrm{b}}$ & $85.95 \pm 2.22^{\mathrm{a}}$ \\
\hline
\end{tabular}

Mean values $(n=5) \pm$ SDs; identical superscripts in row denote no significant $(\alpha<0.05)$ difference between mean values according to Tukey's HSD test (ANOVA)

DW, dry weight; SPoc, substrate of non-enriched P. ostreatus (control); SPoSeZn, substrate of enriched P. ostreatus; Poc, non-enriched P. ostreatus (control); PoSeZn, P. ostreatus enriched with $\mathrm{Se}$ and $\mathrm{Zn} ; \mathrm{SPe}$, substrate of non-enriched $P$. eryngii (control); SPeSeZn, substrate of enriched P. eryngii; Pec, non-enriched P. eryngii (control); PeSeZn, P. eryngii enriched with Se and $\mathrm{Zn}$ 
$\mathrm{kg}$ DW, and it was comparable as in our earlier experiments $[28,30]$. The concentration of $\mathrm{Zn}$ in the control of P. ostreatus was $26.00 \pm 0.82 \mathrm{mg} / \mathrm{kg}$ DW. The enrichment of the substrate with $\mathrm{Se}+\mathrm{Zn}$ resulted in a significant increase in the elements in fruiting bodies up to $109.74 \pm 11.06 \mathrm{mg} / \mathrm{kg}$ DW and $32.926 \pm 0.987 \mathrm{mg} / \mathrm{kg}$ DW $\mathrm{Se}$ and $\mathrm{Zn}$, respectively. The Se concentration in the control of $P$. eryngii was $2.07 \pm 0.68 \mathrm{mg} / \mathrm{kg} \mathrm{DW}$, and a significant rise up to $54.39 \pm 0.79 \mathrm{mg} / \mathrm{kg}$ DW was observed for $\mathrm{Se}+\mathrm{Zn}$-enriched mushrooms. The concentration of $\mathrm{Zn}$ in control and $\mathrm{Se}+\mathrm{Zn}$-enriched P. eryngii was as follows: $22.98 \pm 0.84$ and $85.95 \pm 2.22 \mathrm{mg} / \mathrm{kg} \mathrm{DW}$, respectively. Our experiment confirmed that non-enriched $P$. ostreatus and $P$. eryngii contained $\mathrm{Se}$ and $\mathrm{Zn}$ at the level as in the most popular mushrooms, which range from $<1$ to $20 \mu \mathrm{g} / \mathrm{g}$ DW for Se and from $\sim 5$ to more than $100 \mu \mathrm{g} / \mathrm{g}$ DW for $\mathrm{Zn}$ $[21,25,28,38-44]$. Because mushrooms have great ability to accumulate selected elements [44], supplementation of substrate with different micronutrients was successfully used to enhance their content in fruiting bodies [21, 25, 26, 29]. In our experiment, after Se and $\mathrm{Zn}$ enrichment substrates possessed higher mineral availability for fruiting bodies and it influenced the micronutrient accumulation in mushrooms. The concentration of Se after enrichment was $\sim 40$ and $\sim 27$ times higher for $P$. ostreatus and P. eryngii. The results were consistent with our earlier experiment [28, 30], because the Se concentration in enriched fruiting bodies was significantly higher than in the control. Bhatia et al. [25] revealed that Se-enriched P. florida was able to accumulate even 800 times higher concentration of the micronutrient in comparison with the control. The increase in the content of $\mathrm{Zn}$ in enriched mushroom was slight in $P$. ostreatus, while it was large (nearly 4 times) for P. eryngii.
However, Vieira et al. [27] reported that enrichment with $\mathrm{Zn}$ did not lead to changes of its concentration in the fruiting bodies. Our results for P. eryngii are opposite; the increase in $\mathrm{Zn}$ content in our experiment could be due to an interaction between $\mathrm{Zn}$ and Se which favors increased $\mathrm{Zn}$ content in mushrooms.

Furthermore, the mushroom enrichment is dependent on species, $\mathrm{pH}$, composition of substrate, concentration of the added element and other minerals [45].

\section{Yield, total phenolic, flavonoid and ascorbic acid contents}

The yield of extract ranged from $25.89 \pm 1.88$ to $26.49 \pm 1.23 \mathrm{~g}$ per $100 \mathrm{~g} \mathrm{DW}$ and from $28.15 \pm 0.27$ to $28.85 \pm 2.85 \mathrm{~g}$ per $100 \mathrm{~g}$ DW for $P$. ostreatus and $P$. eryngii (respectively), and there were no significant differences ( $\alpha=0.05$ ) between control and enriched mushrooms (Table 2). The results were higher than those obtained by Yang et al. [46], but similar to Oke and Aslim [47]. Other studies demonstrated that the yield mainly depends on polarity of the solvent $[6,47,48]$. The Folin-Ciocalteu method is a colorimetric method commonly used to determine the total phenolic content $[7,47]$. The Folin-Ciocalteu assay is sensitive to other metabolites, which causes overestimation of the results due to interference of the metabolites with the reagent, and therefore, the method is not specific for the determination of total phenolic content [5]. To improve the specificity for total phenolic content determination in our study, modifications suggested by SánchezRangel et al. [32] involving the simultaneous quantification of total ascorbic acid by the Folin-Ciocalteu assay were applied. The total phenolic content in non-enriched
Table 2 Extraction yield, total phenolic, flavonoid and ascorbic acid contents and $\mathrm{EC}_{50}$ value in P. ostreatus and P. eryngii fruiting bodies

\begin{tabular}{|c|c|c|}
\hline & Poc & PoSeZn \\
\hline Yield (g/100 g DW) & $25.89 \pm 1.88^{\mathrm{a}}$ & $26.49 \pm 1.23^{\mathrm{a}}$ \\
\hline TPC (mg/g of extract) & $9.64 \pm 0.33^{\mathrm{b}}$ & $13.38 \pm 0.58^{\mathrm{a}}$ \\
\hline TFC (mg/g of extract) & $2.11 \pm 0.19^{\mathrm{b}}$ & $2.72 \pm 0.09^{\mathrm{a}}$ \\
\hline $\mathrm{AAC}(\mathrm{mg} / 100 \mathrm{~g} \mathrm{DW})$ & $10.28 \pm 0.39^{b}$ & $15.76 \pm 0.57^{\mathrm{a}}$ \\
\hline \multirow[t]{2}{*}{$\mathrm{EC}_{50}(\mathrm{mg} / \mathrm{mL})(\mathrm{DPPH})$} & $4.42 \pm 0.08^{\mathrm{a}}$ & $3.84 \pm 0.09^{b}$ \\
\hline & Pec & PeSeZn \\
\hline Yield (g/100 g DW) & $28.85 \pm 2.85^{\mathrm{a}}$ & $28.15 \pm 0.27^{\mathrm{a}}$ \\
\hline TPC (mg/g of extract) & $7.91 \pm 1.02^{\mathrm{b}}$ & $10.86 \pm 1.48^{\mathrm{a}}$ \\
\hline TFC (mg/g of extract) & $1.26 \pm 0.17^{\mathrm{b}}$ & $1.89 \pm 0.09^{\mathrm{a}}$ \\
\hline AAC (mg/100 g DW) & $16.64 \pm 0.47^{b}$ & $34.74 \pm 1.99^{\mathrm{a}}$ \\
\hline $\mathrm{EC}_{50}(\mathrm{mg} / \mathrm{mL})(\mathrm{DPPH})$ & $7.34 \pm 0.11^{\mathrm{a}}$ & $3.35 \pm 0.11^{\mathrm{b}}$ \\
\hline
\end{tabular}

Mean values $(n=5) \pm$ SDs; identical superscripts in row denote no significant $(\alpha<0.05)$ difference between mean values according to Tukey's HSD test (ANOVA)

DW, dry weight; TPC, total phenolic content; TFC, total flavonoid content; AAC, ascorbic acid content; Poc, non-enriched P. ostreatus (control); PoSeZn, P. ostreatus enriched with Se and $\mathrm{Zn}$; Pec, non-enriched P. eryngii (control); PeSeZn, P. eryngii enriched with Se and $\mathrm{Zn}$ 
mushrooms for P. ostreatus and P. eryngii was $9.64 \pm 0.33$ and $7.91 \pm 1.02 \mathrm{mg} / \mathrm{g}$ of extract, respectively. The total flavonoid content was $2.11 \pm 0.19$ and $1.26 \pm 0.17 \mathrm{mg} / \mathrm{g}$ of extract, respectively. It was documented that major components of mushroom extract are phenolics and Pleurotus species exhibited different contents of total phenolic ranging from $\sim 2$ to $>30 \mathrm{mg} / \mathrm{g}$ of extract $[27,37,49]$. In comparison with our earlier study [28], the results obtained for non-enriched mushrooms were slightly higher. The reason should be sought in the composition of substrates. It has been reported that mushrooms contain different compounds of phenolics. Some authors have stated that mushrooms contain mainly phenolics acids $[7,50]$, while others reported a high amount of flavonoids in extracts $[5,37,51]$. The total flavonoid content in different species of Pleurotus was found at the level from 1.2 to $2.9 \mu \mathrm{g} / \mathrm{g}$ of extract [49], even to $7.79 \mathrm{mg} / \mathrm{g}$ of extract [37]. However, Vieira et al. [27] did not detect flavonoids in P. ostreatus. It was found that AAC was dependent on species and ranged from $<5$ up to as high as $50 \mathrm{mg} / 100 \mathrm{~g}$ DW [40, 52, 53]. In our experiment, the ascorbic acid level in non-enriched Pleurotus species ranged from $10.28 \pm 0.39$ to $16.64 \pm 0.47 \mathrm{mg} / 100 \mathrm{~g}$ DW. The enrichment of substrates with Se and $\mathrm{Zn}$ resulted in significant increases in TPC, TFC and AAC. It was documented that Se treatments enhanced the phenolic content in plants and mushrooms [26, 54, 55]. However, no changes of phenolic content in zinc-enriched $P$. ostreatus were detected by Vieira [27]. In the case of Se, it was suggested that the element enhances accumulation of some sugars [54] or inhibits enzymatic polyphenol oxidation [26], while $\mathrm{Zn}$ is involved in the regulation of sugar metabolism [56, 57]. Thus, the mechanism is probably related to changes in concentration of glucose, which is an important substrate in many metabolic pathways, and in that way enhanced the phenolic content. Additionally, $\mathrm{Zn}$ was able to induce oxidative stress [58] and in consequence stimulate synthesis of antioxidants such as ascorbic acid and phenolics. The higher content of the metabolites in enriched mushrooms could be the result of detoxification mechanisms caused by elevated levels of the elements.

\section{Chromatographic profile}

In the study, we used 22 standards for identification of phenolics, among which the phenolic acids and flavonoids were detected in substrates and Pleurotus species. In substrates, caffeic, chlorogenic, ferulic, syringic, $p$-coumaric, vanillic and $t$-cinnamic acids and naringenin were detected (Table 3). We quantified derivatives of benzoic (4-hydroxybenzoic, 2,5-dihydroxybenzoic, protocatechuic and vanillic acids) and $t$-cinnamic acids ( $p$-coumaric, ferulic and $t$-cinnamic acids) and flavanones (naringenin) in fruiting bodies (Table 4). Six phenolic acids were detected in the extract from $P$. ostreatus: 4-hydroxybenzoic, ferulic, $p$-coumaric, protocatechuic, $t$-cinnamic and vanillic acids. Additionally, naringenin was also quantified. The extract from $P$. eryngii additionally contained 2,5-dihydroxybenzoic acid. Among the compounds, ferulic acid was dominant in both analyzed Pleurotus species. The monitoring of chromatograms showed that mushroom contains different phenolic compounds [5, 7, 47, 50]. In our previous experiment [28], we detected only 4-hydroxybenzoic, $p$-coumaric, ferulic acids and myricetin. The differences could be due to the impact of $\mathrm{Zn}$ on phenolic composition. Additionally, substrates could have influenced phenolics in fruiting bodies because of decomposition of lignin by mycelium. This polymer contains in the structure some phenolic acids or their derivatives. Woldegiorgis et al. [7] detected in P. ostreatus caffeic, gallic and $p$-hydroxybenzoic acids and myricetin. Kim et al. [59] additionally quantified homogentisic, protocatechuic, chlorogenic acids, naringin and myricetin. The study of $P$. ostreatus by Palacios et al. [5] confirmed $p$-coumaric, ferulic, gallic, gentisic, $p$-hydroxybenzoic, homogentisic and protocatechuic acids and myricetin in fruiting bodies. Kim
Table 3 Phenolic acid and flavonoid composition of substrates $(\mu \mathrm{g} / \mathrm{g} \mathrm{DW})$

\begin{tabular}{lllll}
\hline Compounds & SPoc & SPoSeZn & SPec & SPeSeZn \\
\hline Chlorogenic acid & $2.50 \pm 0.09^{\mathrm{a}}$ & $2.70 \pm 0.11^{\mathrm{a}}$ & $1.27 \pm 0.18^{\mathrm{a}}$ & $1.49 \pm 0.40^{\mathrm{a}}$ \\
Syringic acid & $2.30 \pm 0.19^{\mathrm{b}}$ & $3.70 \pm 0.11^{\mathrm{a}}$ & $2.22 \pm 0.22^{\mathrm{b}}$ & $3.87 \pm 0.22^{\mathrm{a}}$ \\
Ferulic acid & $3.00 \pm 0.33^{\mathrm{b}}$ & $4.46 \pm 0.24^{\mathrm{a}}$ & $4.87 \pm 0.33^{\mathrm{b}}$ & $6.29 \pm 0.47^{\mathrm{a}}$ \\
$p$-Coumaric acid & $7.17 \pm 0.23^{\mathrm{b}}$ & $9.12 \pm 0.12^{\mathrm{a}}$ & $6.49 \pm 0.22^{\mathrm{b}}$ & $8.00 \pm 0.18^{\mathrm{a}}$ \\
Caffeic acid & $1.21 \pm 0.08^{\mathrm{b}}$ & $2.52 \pm 0.09^{\mathrm{a}}$ & $1.23 \pm 0.21^{\mathrm{b}}$ & $3.81 \pm 0.17^{\mathrm{a}}$ \\
$t$-Cinnamic acid & $2.35 \pm 0.15^{\mathrm{b}}$ & $5.97 \pm 0.59^{\mathrm{a}}$ & $2.79 \pm 0.18^{\mathrm{a}}$ & $2.69 \pm 0.11^{\mathrm{a}}$ \\
Vanillic acid & $1.34 \pm 0.06^{\mathrm{b}}$ & $3.87 \pm 0.52^{\mathrm{a}}$ & $1.59 \pm 0.22^{\mathrm{b}}$ & $2.85 \pm 0.18^{\mathrm{a}}$ \\
Naringenin & $0.15 \pm 0.03^{\mathrm{b}}$ & $0.53 \pm 0.17^{\mathrm{a}}$ & $0.42 \pm 0.04^{\mathrm{b}}$ & $0.63 \pm 0.09^{\mathrm{a}}$ \\
\hline
\end{tabular}

Mean values $(n=5) \pm$ SDs; identical superscripts in rows for each mushroom species denote no significant $(p<0.05)$ difference between mean values according to Tukey's HSD test (ANOVA)

SPoc, substrate of non-enriched P. ostreatus (control); SPoSeZn, substrate of enriched P. ostreatus; SPec, non-enriched $P$. ostreatus (control); SPeSeZn, substrate of enriched $P$. eryngii 
Table 4 Phenolic acid and flavonoid composition of $P$. ostreatus and P. eryngii $(\mu \mathrm{g} / \mathrm{g}$ DW)

\begin{tabular}{lllrr}
\hline Compounds & Poc & PoSeZn & \multicolumn{1}{l}{ Pec } & \multicolumn{1}{c}{ PeSeZn } \\
\hline 2,5-Dihydroxybenzoic acid & nd & nd & $1.37 \pm 0.30^{\mathrm{b}}$ & $5.49 \pm 0.41^{\mathrm{a}}$ \\
4-Hydroxybenzoic acid & $5.30 \pm 0.20^{\mathrm{b}}$ & $6.70 \pm 0.19^{\mathrm{a}}$ & $2.32 \pm 0.32^{\mathrm{b}}$ & $3.59 \pm 0.20^{\mathrm{a}}$ \\
Ferulic acid & $30.00 \pm 1.00^{\mathrm{b}}$ & $34.46 \pm 2.94^{\mathrm{a}}$ & $29.00 \pm 1.00^{\mathrm{b}}$ & $36.29 \pm 1.47^{\mathrm{a}}$ \\
$p$-Coumaric acid & $10.54 \pm 0.70^{\mathrm{b}}$ & $15.82 \pm 1.02^{\mathrm{a}}$ & $13.49 \pm 2.22^{\mathrm{b}}$ & $20.00 \pm 0.88^{\mathrm{a}}$ \\
Protocatechuic acid & $0.21 \pm 0.09^{\mathrm{b}}$ & $0.52 \pm 0.07^{\mathrm{a}}$ & $1.43 \pm 0.24^{\mathrm{b}}$ & $7.81 \pm 1.67^{\mathrm{a}}$ \\
$t$-Cinnamic acid & $0.35 \pm 0.05^{\mathrm{b}}$ & $0.97 \pm 0.05^{\mathrm{a}}$ & $0.79 \pm 0.15^{\mathrm{b}}$ & $1.69 \pm 0.01^{\mathrm{a}}$ \\
Vanillic acid & $0.34 \pm 0.03^{\mathrm{b}}$ & $0.87 \pm 0.12^{\mathrm{a}}$ & $0.59 \pm 0.04^{\mathrm{b}}$ & $0.85 \pm 0.18^{\mathrm{a}}$ \\
Naringenin & $0.18 \pm 0.05^{\mathrm{b}}$ & $0.73 \pm 0.18^{\mathrm{a}}$ & $0.18 \pm 0.04^{\mathrm{b}}$ & $0.43 \pm 0.09^{\mathrm{a}}$ \\
\hline
\end{tabular}

Mean values $(n=5) \pm$ SDs; identical superscripts in rows for each mushroom species denote no significant $(p<0.05)$ difference between mean values according to Tukey's HSD test (ANOVA)

Poc, non-enriched P. ostreatus (control); PoSeZn, P. ostreatus enriched with Se and Zn; Pec, non-enriched P. eryngii (control); PeSeZn, P. eryngii enriched with Se and $\mathrm{Zn}$ et al. [59] examined P. eryngii and documented gallic and protocatechuic acids and naringin in the mushroom. According to Reis et al. [50] in P. ostreatus and P. eryngii, the presence of protocatechuic, $p$-hydroxybenzoic, $p$-coumaric and cinnamic acids was found. Oke and Aslim [47] quantified gallic, $p$-hydroxybenzoic, caffeic, syringic, $p$-coumaric, ferulic and cinnamic acids and catechin in $P$. eryngii. In other species of mushroom, additionally $\alpha$-resorcylic and syringic acids were detected $[6,7,59]$. Flavonoids or their aglycones (myricetin, quercetin, naringenin, kaempferol and hesperetin) were also detected in different species of edible mushroom $[5,7,59]$ (although neither fungi nor animals, but only plants have the ability to biosynthesize flavonoids [60]).

Activation of synthesis of free phenolic acids was also observed in our previous study [28] as well as in L. sativus [61]. As mentioned above, it could be the result of the elements on metabolism of sugars and in consequence on metabolism of other biomolecules.

Table 2 presents DPPH scavenging ability expressed as $\mathrm{EC}_{50}$ values. Better scavenging ability for non-enriched mushroom was obtained for P. ostreatus $(4.42 \mathrm{mg} / \mathrm{mL})$. The drop in $\mathrm{EC}_{50}$ values observed for enriched mushroom confirmed improvement of the antioxidant properties. Additionally, both enriched species of Pleurotus had similar $\mathrm{EC}_{50}$ values. Scavenging effects on DPPH of extract from non-enriched mushroom increased with concentrations (Fig. 1). For P. ostreatus, it ranged from 19.7 to $76.7 \%$, and for P. eryngii, it was between 17.9 and $62.1 \%$. The Se and $\mathrm{Zn}$ addition resulted in increases in the scavenging effects by $35.8-87.8$ and $40.3-91.4 \%$, respectively. In other experiments $\mathrm{EC}_{50}$ values for $P$. ostreatus were $8.4 \mathrm{mg} / \mathrm{mL}$ [7] and $6.54 \mathrm{mg} / \mathrm{mL}$ [50], while $\mathrm{EC}_{50}$ value for $P$. eryngii was $8.67 \mathrm{mg} / \mathrm{mL}$ [50]. Se-rich mushroom showed a larger DPPH scavenging effect than non-enriched mushroom [26, 28]. In the study, we demonstrated that simultaneous supplementation of micronutrients significantly affected the antioxidant properties.

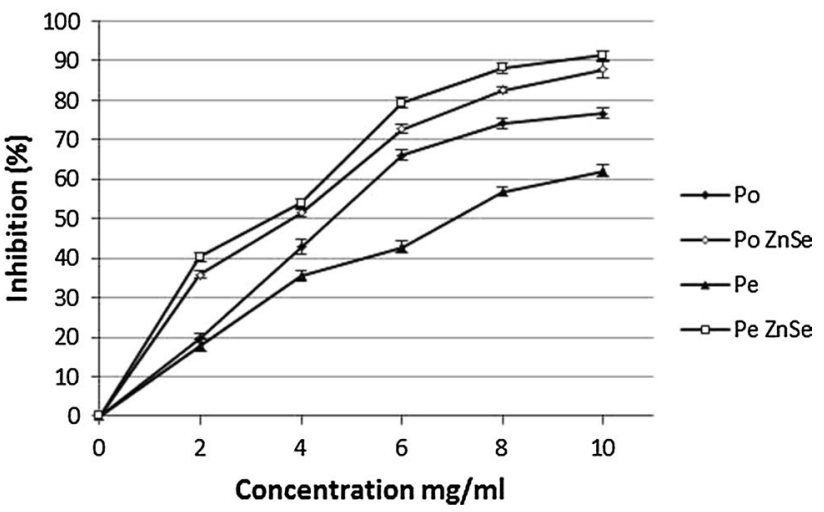

Fig. 1 Scavenging ability of methanolic extracts from $P$. ostreatus and $P$. eryngii on 2,2-diphenyl-1-picrylhydrazyl (DPPH) radicals. Each value is expressed as mean \pm SDs $(n=5)$. Po, non-enriched $P$. ostreatus; PoZnSe, enriched P. ostreatus; Pe, non-enriched P. eryngii; PeZnSe, non-enriched $P$. eryngii

The correlation between the total phenolic content and antioxidant activity in mushroom was confirmed [62]. In our previous study for enriched $P$. ostreatus, a correlation between inhibition of the radicals and the total phenolic and flavonoid content was found, whereas Vieira et al. [27] found no correlations for iron-, zinc- and lithium-enriched $P$. ostreatus. In the present study for P. ostreatus, we found a correlation between $\mathrm{EC}_{50}$ value and phenolic compounds (except naringin) and $\mathrm{Zn}$ and Se concentration in fruiting bodies and between micronutrient concentrations and phenolic compounds (except ferulic acids) (Table 5). For $P$. eryngii, strong correlations were found between $\mathrm{EC}_{50}$ value and phenolic compounds (except vanillic acid) and $\mathrm{Zn}$ and Se concentrations in fruiting bodies and between micronutrient concentrations and phenolic compounds (except vanillic acid) (Table 6). Ions of some metals including $\mathrm{Zn}$ can form a complex with polyphenols [63]. Moreover, phenolics complexed by metals have reduced antioxidant 
Table 5 Pearson correlation coefficients $(r)$ between Se and $\mathrm{Zn}$ concentrations in fruiting bodies and $\mathrm{EC}_{50}$, phenolic and flavonoid components and between $\mathrm{EC}_{50}$ and phenolic and flavonoid components for $P$. ostreatus

\begin{tabular}{llll}
\hline Compounds & $\mathrm{EC}_{50}$ & $\mathrm{Se}$ & $\mathrm{Zn}$ \\
\hline 4-Hydroxybenzoic acid & -0.922 & 0.967 & 0.918 \\
Protocatechuic acid & -0.822 & 0.950 & 0.859 \\
Vanillic acid & -0.822 & 0.988 & 0.925 \\
$p$-Coumaric acid & -0.935 & 0.949 & 0.969 \\
Ferulic acid & -0.910 & $\mathrm{~ns}$ & $\mathrm{~ns}$ \\
$t$-Cinnamic acid & -0.901 & 0.995 & 0.948 \\
Naringin & $\mathrm{ns}$ & 0.955 & 0.906 \\
TPC & -0.950 & 0.988 & 0.969 \\
TFC & -0.999 & 0.987 & 0.938 \\
AAC & -0.999 & 0.989 & 0.973 \\
EC & & -0.893 & -0.914 \\
Se & -0.893 & & 0.967 \\
Zn & -0.914 & 0.967 & \\
\hline
\end{tabular}

TPC, total phenolic content; TFC, total flavonoid content; AAC, ascorbic acid content

Table 6 Pearson correlation coefficients $(r)$ between Se and $\mathrm{Zn}$ concentration in the fruiting bodies and $\mathrm{EC}_{50}$, phenolic and flavonoid components and between $\mathrm{EC}_{50}$ and phenolic and flavonoid components for P. eryngii

\begin{tabular}{llll}
\hline Compounds & $\mathrm{EC}_{50}$ & $\mathrm{Se}$ & $\mathrm{Zn}$ \\
\hline 2,5-Dihydroxybenzoic acid & -0.988 & 0.989 & 0.987 \\
4-Hydroxybenzoic acid & -0.946 & 0.950 & 0.957 \\
Protocatechuic acid & -0.946 & 0.954 & 0.945 \\
Vanillic acid & $\mathrm{ns}$ & $\mathrm{ns}$ & $\mathrm{ns}$ \\
$p$-Coumaric acid & -0.926 & 0.951 & 0.929 \\
Ferulic acid & -0.953 & 0.959 & 0.952 \\
$t$-Cinnamic acid & -0.984 & 0.983 & 0.977 \\
Naringin & -0.902 & 0.902 & 0.892 \\
TPC & -0.978 & 0.995 & 0.993 \\
TFC & -0.882 & 0.882 & 0.873 \\
AAC & -0.999 & 0.999 & 0.999 \\
EC ${ }_{50}$ & & -0.999 & -0.998 \\
Se & -0.999 & & 0.999 \\
Zn & -0.998 & 0.999 & \\
\hline
\end{tabular}

TPC, total phenolic content; TFC, total flavonoid content; AAC, ascorbic acid content

activity, because of the limited availability of free radicals for donation [27, 63]. On the other hand, high content of metals in enriched mushroom can result in bioavailability of the metals. Thus, higher content of $\mathrm{Zn}$ and other metals bioavailable in mushrooms may result in lower complexation with polyphenols. In this context, the increase in antioxidant activity (represented by DPPH) observed in our experiment could be the result of the fact that the formation of complexes was reduced or other compounds exhibiting higher antioxidant activity were formed. Also interaction between Se and $\mathrm{Zn}$ could affect the bioavailability of metals and consequently the formation of complexes. Despite the reduction of antioxidant properties of some elements including $\mathrm{Zn}$ [27], our results with simultaneous supplementation with $\mathrm{Zn}$ and Se provide the opportunity to improve antioxidant properties and antioxidant contents in enriched mushrooms.

To conclude, the enrichment is a good practice to enhance the mineral content in mushrooms. Additionally, the obtained results demonstrated that simultaneous enrichment with micronutrients with contrary effects on antioxidant properties can activate synthesis of phenolic compounds and ascorbic acid. The micronutrient supplementation of substrates caused improvement of the antioxidant properties and increased content of phenolic compounds in enriched fruiting bodies of $P$. ostreatus and $P$. eryngii in comparison with the controls.

The present study is part of experiments with simultaneous enrichment of mushrooms, which focuses on estimating the impact of minerals on antioxidant properties of edible mushrooms. The investigation is the first study evaluating the effect of addition of two elements to the substrate at the same time on antioxidant properties of mushrooms. Further studies on $\mathrm{Se}$ and other micronutrients are in progress.

\section{Compliance with ethical standards}

Conflict of interest None.

Compliance with ethics requirements This article does not contain any studies with human or animal subjects.

Open Access This article is distributed under the terms of the Creative Commons Attribution 4.0 International License (http://creativecommons.org/licenses/by/4.0/), which permits unrestricted use, distribution, and reproduction in any medium, provided you give appropriate credit to the original author(s) and the source, provide a link to the Creative Commons license, and indicate if changes were made.

\section{References}

1. Ajith TA, Janardhanan KK (2007) Indian medicinal mushrooms as a source of antioxidant and antitumor agents. Clin Biochem Nutr 40:157-162. doi:10.3164/jcbn.40.157

2. Helano SA, Barros L, Martins A, Queiroz P, Santos-Buelga C, Ferreira ICFR (2012) Fruiting body, spores and in vitro produced mycelium of Ganoderma lucidum from Northeast Portugal: a comparative study of the antioxidant potential of phenolic and polysaccharidic extracts. Food Res Int 46:135-140. doi:10.1016/j.foodres.2011.12.009 
3. Kwon AH, Qiu DM, Hashimoto ZDM, Yamamoto M, Kimura KT (2009) Effects of medicinal mushroom (Sparassis crispa) on wound healing in streptozotocin-induced diabetic rats. Am J Surg 197:503-509. doi:10.1016/j.amjsurg.2007.11.021

4. Ofodile LN, Uma NU, Kokubun T, Grayer RJ, Ogundipe OT, Simmonds MS (2005) Antimicrobial activity of some Ganoderma species from Nigeria. Phytother Res 19:310-313. doi:10.1002/ptr.1641

5. Palacios I, Lozano M, Moro C, D'Arrigo M, Rostagno MA, Martínez JA, García-Lafuente A, Guillamón E (2011) Antioxidant properties of phenolic compounds occurring in edible mushrooms. Food Chem 128:674-678. doi:10.1016/j. foodchem.2011.03.085

6. Li H, Park S, Moon B, Yoo Y, Lee Y, Lee C (2012) Targeted phenolic analysis in Hericium erinaceum and its antioxidant activities. Food Sci Biotechnol 21:881-888. doi:10.1007/ s10068-012-0114-1

7. Woldegiorgis AZ, Abate D, Haki GD, Ziegler GR (2014) Antioxidant property of edible mushrooms collected from Ethiopia. Food Chem 157:30-36. doi:10.1016/j.foodchem.2014.02.014

8. Jose N, Ajith TA, Janardhanan KK (2002) Antioxidant, antiinflammatory, and antitumor activities of culinary-medicinal mushroom Pleurotus pufmonanus (Fr.) Quel. (Agaricomycetideae). Int J Med Mushrooms 4:329-335. doi:10.1615/IntJMedMushr. v4.i4.60

9. Oboh G, Ademosun AO (2012) Characterization of the antioxidant properties of phenolic extracts from some citrus peels. $\mathrm{J}$ Food Sci Technol 49:729-736. doi:10.1007/s13197-010-0222-y

10. Graversen HB, Becker EM, Skibsted LH, Andersen ML (2008) Antioxidant synergism between fruit juice and $\alpha$-tocopherol. A comparison between high phenolic black chokeberry (Aronia melanocarpa) and high ascorbic blackcurrant (Ribes nigrum). Eur Food Res Technol 226:737-743. doi:10.1007/ s00217-007-0585-0

11. Hu FB (2002) Dietary pattern analysis: a new direction in nutritional epidemiology. Curr Opin Lipidol 13:3-9

12. Prasad AS, Bao B, Beck FWJ, Kucuk O, Sarkar FH (2004) Antioxidant effect of zinc in humans. Free Radic Biol Med 37:11821190. doi:10.1016/j.freeradbiomed.2004.07.007

13. Willcox JK, Ash SL, Catignani GL (2004) Antioxidants and prevention of chronic disease. Rev Food Sci Nutr 44:275-295

14. Valko M, Rhodes CJ, Moncol J, Izakovic M, Mazur M (2006) Free radicals, metals and antioxidants in oxidative stressinduced cancer. Chem Biol Interact 160:1-40. doi:10.1016/j. cbi.2005.12.009

15. Michalak A (2006) Phenolic compounds and their antioxidant activity in plants growing under heavy metal stress. Pol J Environ Stud 15:523-530

16. Newell AM, Yousef GG, Lila MA, Ramírez-Mares MV, de Mejia EG (2010) Comparative in vitro bioactivities of tea extracts from six species of Ardisia and their effect on growth inhibition of HepG2 cells. J Ethnopharmacol 130:536-544. doi:10.1016/j. jep.2010.05.051

17. Côté J, Caillet $\mathrm{S}$, Doyon $\mathrm{G}$, Sylvain JF, Lacroix $\mathrm{M}$ (2010) Bioactive compounds in cranberries and their biological properties. Crit Rev Food Sci Nutr 50:666-679. doi:10.1080/10408390903044107

18. Panel on Dietary Antioxidants and Related Compounds, Subcommittees on Upper Reference Levels of Nutrients and Interpretation and Uses of DRIs, Standing Committee on the Scientific Evaluation of Dietary Reference Intakes, Food and Nutrition Board, Institute of Medicine (2000) Vitamin C. In: Dietary references intakes for vitamin C, vitamin E, selenium and carotenoids. National Academy Press, Washington, DC, pp 95-185

19. FAO/WHO (2002) Vitamin C. In: Human vitamin and mineral requirements. Report of a join FAO/WHO consultation; Bankok,
Thailand. Food and Agriculture Organization of the United Nations (FAO),Word Health Organization, Rome, pp 73-86

20. Brenneisen P, Steinbrenner H, Sies H (2005) Selenium, oxidative stress, and health aspects. Mol Aspects Med 26:256-267. doi:10.1016/j.mam.2005.07.004

21. Estrada AER, Lee HJ, Beelman RB, del Mar Jimenez-Gasco M, Royse DJ (2009) Enhancement of the antioxidants ergothioneine and selenium in Pleurotus eryngii var. eryngii basidiomata through cultural practices. World J Microbiol Biotechnol 25:1597-1607. doi:10.1007/s11274-009-0049-8

22. Riaz M, Mehmood KT (2012) Selenium in human health and disease: a review. J Postgrad Med 26:120-133

23. Tinggi U (2008) Selenium: its role as antioxidant in human health. Environ Health Prev Med 13:102-108. doi:10.1007/ s12199-007-0019-4

24. Ho E, Courtemanche C, Ames BN (2003) Zinc deficiency induces oxidative DNA damage and increases p53 expression in human lung fibroblasts. J Nutr 133:2543-2548

25. Bhatia P, Aureli F, D'Amato M, Prakash R, Cameatra SS, Nagaraja TP, Cubadda F (2013) Selenium bioaccessibility and speciation in biofortified Pleurotus mushrooms growth on selenium-rich agricultural residues. Food Chem 140:225-230. doi:10.1016/j.foodchem.2013.02.054

26. Bhatia P, Prakash R, Prakash NT (2014) Enhanced antioxidant properties as a function of selenium uptake by edible mushrooms cultivated on selenium-accumulated waste post-harvest wheat and paddy residues. Int J Recycl Org Waste Agric 3:127-132. doi:10.1007/s40093-014-0074-y

27. Vieira FPA, Gontijo DC, Vieira BC, Fontes EAF, de Assunção LS, Leite JPV, Oliveira MGA, Kasuya MCM (2013) Antioxidant activities, total phenolics and metal contents in Pleurotus ostreatus mushrooms enriched with iron, zinc or lithium. LWT Food Sci Technol 54:421-425. doi:10.1016/j.lwt.2013.06.016

28. Gąsecka M, Mleczek M, Siwulski M, Niedzielski P, Kozak L (2015) The effect of selenium on phenolics and flavonoids in selected edible white rot fungi. LWT Food Sci Technol 63:726731. doi:10.1016/j.lwt.2015.03.046

29. Niedzielski P, Mleczek M, Siwulski M, Gąsecka M, Kozak L, Rissmann I, Mikołajczak P (2014) Efficacy of supplementation of selected medicinal mushrooms with inorganic selenium salts. J Environ Sci Health B 49:929-937. doi:10.1080/03601234.201 4.951576

30. Niedzielski P, Mleczek M, Siwulski M, Gąsecka M, Kozak L (2015) Supplementation of cultivated mushroom species with selenium: bioaccumulation and speciation study. Eur Food Res Technol. doi:10.1007/s00217-015-2474-2

31. Dewanto V, Wu X, Liu RH (2002) Processed sweet corn has higher antioxidant activity. J Agric Food Chem 50:4959-4964. doi:10.1021/jf0255937

32. Sánchez-Rangel JC, Benavides JJ, Heredia BJ, Cisneros-Zevallos L, Jacobo-Velázquez DA (2013) The Folin-Ciocalteu assay revisited: improvement of its specificity for total phenolic content determination. Anal Methods 5:5990-5999. doi:10.1039/ C3AY41125G

33. Isabelle M, Lee BL, Lim MT, Koh WP, Huang D, Ong CN (2010) Antioxidant activity and profiles of common vegetables in Singapore. Food Chem 120:993-1003. doi:10.1016/j. foodchem.2009.11.038

34. Choi Y, Lee SM, Chun J, Lee HB, Lee J (2006) Influence of heat treatment on the antioxidant activities and polyphenolic compounds of Shiitake (Lentinus edodes) mushroom. Food Chem 99:381-387. doi:10.1016/j.foodchem.2005.08.004

35. Lin JY, Tang CY (2007) Determination of total phenolic and flavonoid contents in selected fruits and vegetables, as well as their stimulatory effects on mouse splenocyte proliferation. Food Chem 101:140-147. doi:10.1016/j.foodchem.2006.01.014 
36. Buśko M, Góral T, Ostrowska A, Matysiak A, WalentynGóral D, Perkowski J (2014) The effect of Fusarium inoculation and fungicide application on concentrations of flavonoids (apigenin, kaempferol, luteolin, naringenin, quercetin, rutin, vitexin) in winter wheat cultivars. Am J Plant Sci 5:3727-3736. doi:10.4236/ajps.2014.525389

37. Sudha G, Vadivukkarasi S, Shree RBI (2012) Antioxidant activity of various extracts from an edible mushroom Pleurotus eous. Food Sci Biotechnol 21:661-668

38. Falandysz J (2008) Selenium in edible mushrooms. J Environ Sci Health C 26:256-299. doi:10.1080/10590500802350086

39. Cost-Silva F, Marques G, Matos CC, Barros AIRNA, Nunes FN (2011) Selenium contents of Portuguese commercial and wild edible mushrooms. Food Chem 126:91-96. doi:10.1016/j. foodchem.2010.10.082

40. Çaglarlrmak N, Ünal K, Ötles S (2002) Nutritional value of edible wild mushrooms collected from the black sea region of Turkey. Micol Aplicada Int 14:1-5

41. Vetter J, Hajdú C, Gyorfi J, Maszlavér P (2005) Mineral composition of the cultivated mushrooms Agaricus bisporus, Pleurotus ostreatus and Lentinula edodes. Acta Aliment 34:441-451. doi:10.1556/AAlim34.2005.4.11

42. Turkekul I, Elmastas M, Tüzen M (2004) Determination of iron, copper, manganese, zinc, lead, and cadmium in mushroom samples from Tokat, Turkey. Food Chem 84:389-392. doi:10.1016/ S0308-8146(03)00245-0

43. Isildak Ö, Turkekul I, Elmastaş M, Tüzen M (2004) Analysis of heavy metals in some wild-grown edible mushrooms from the middle black sea region, Turkey. Food Chem 86:547-552. doi:10.1016/j.foodchem.2003.09.007

44. Kalač P (2009) Chemical composition and nutritional value of European species of wild growing mushrooms: a review. Food Chem 113:9-16. doi:10.1016/j.foodchem.2008.07.077

45. de Assunção LS, da Luz JM, da Silva MDC, Vieira PA, Bazzolli DM, Vanetti MC, Kasuya MC (2012) Enrichment of mushrooms: an interesting strategy for the acquisition of lithium. Food Chem 134:1123-1127. doi:10.1016/j.foodchem.2012.03.044

46. Yang JH, Lin HC, Mau JL (2002) Antioxidant properties of several commercial mushrooms. Food Chem 77:229-235. doi:10.1016/S0308-8146(01)00342-9

47. Oke F, Aslim B (2011) Protective effect of two edible mushrooms against oxidative cell damage and their phenolic composition. Food Chem 128:613-619. doi:10.1016/j.foodchem.2011.03.036

48. Naczk M, Shahidi F (2006) Phenolics in cereals, fruits and vegetables: occurrence, extraction and analysis. J Pharm Biomed 41:1523-1542

49. Babu DR, Pandey M, Rao GN (2014) Antioxidant and electrochemical properties of cultivated Pleurotus spp. and their sporeless/low sporing mutants. J Food Sci Tech 51:3317-3324. doi:10.1007/s13197-012-0822-9

50. Reis FS, Martins A, Barros L, Ferreira IC (2012) Antioxidant properties and phenolic profile of the most widely appreciated cultivated mushrooms: a comparative study between in vivo and in vitro samples. Food Chem Toxicol 50:1201-1207. doi:10.1016/j.fct.2012.02.013
51. Ahmad R, Muniandy S, Shukri NIA, Alias SMU, Hamid AA, Yusoff WMW, Senafi S, Daud F (2014) Antioxidant properties and glucan compositions of various crude extract from Lentinus squarrosulus mycelial culture. Adv Biosci Biotechnol 5:805814. doi:10.4236/abb.2014.510094

52. Singdevsachan SK, Patra JK, Thatoi H (2013) Nutritional and bioactive potential of two wild edible mushrooms (Lentinus sajor-caju and Lentinus torulosus) from Similipal Biosphere Reserve, India. Food Sci Biotechnol 22:137-145. doi:10.1007/ s10068-013-0019-7

53. Singdevsachan SK, Patra JK, Tayung K, Tayung K, Sarangi K, Hrudayanath T (2014) Evaluation of nutritional and nutraceutical potentials of three wild edible mushrooms from Similipal Biosphere Reserve, Odisha, India. J Verbrauch Lebensm 9:111-120. doi:10.1007/s00003-014-0861-4

54. Lei C, Ma Q, Tang QY, Ai XR, Zhou Z, Yao L, Wang Y, Wang Q, Dong JZ (2014) Sodium selenite regulates phenolics accumulation and tuber development of purple potatoes. Sci Hortic 165:142-147. doi:10.1016/j.scienta.2013.10.024

55. Sae-Lee N, Kerdchoechuen O, Laohakunjit N (2012) Chemical qualities and phenolic compounds of Assam tea after soil drench application of selenium and aluminum. Plant Soil 356:381-393. doi:10.1007/s11104-012-1139-1

56. Mukhopadhyay M, Das A, Subba P, Bantawa P, Sarkar B, Ghosh P, Mondal TK (2013) Structural, physiological, and biochemical profiling of tea plantlets under zinc stress. Biol Plant 57:474480. doi:10.1007/s10535-012-0300-2

57. Hajiboland R, Amirazad F (2010) Growth, photosynthesis and antioxidant defense system in Zn-deficient red cabbage plants. Plant Soil Environ 56:209-217

58. Tripathi BN, Gaur JP (2004) Relationship between copper- and zinc-induced oxidative stress and proline accumulation in Scenedesmus sp. Planta 219:397-404. doi:10.1007/ s00425-004-1237-2

59. Kim MY, Seguin P, Ahn JK, Kim JJ, Chun SC, Kim EH, Seo SH, Kang EY, Kim SL, Park YJ, Ro HM, Chung IM (2008) Phenolic compound concentration and antioxidant activities of edible and medicinal mushrooms from Korea. J Agric Food Chem 56:72657270. doi:10.1021/jf8008553

60. Iwashina $\mathrm{T}(2000)$ The structure and distribution of the flavonoids in plants. J Plant Res 113:287-299. doi:10.1007/ PL00013940

61. Elguera JCT, Barrientos EY, Wrobel K, Wrobel K (2013) Effect of cadmium (Cd(II)), selenium (Se(IV)) and their mixtures on phenolic compounds and antioxidant capacity in Lepidium sativum. Acta Physiol Plant 35:2431-2441. doi:10.1007/ s11738-012-1086-8

62. Puttaraju NG, Venkateshaia SN, Dharmesh MS, Urs SMN, Somasundaram R (2006) Antioxidant activity of indigenous edible mushrooms. J Agric Food Chem 54:9764-9772. doi:10.1021/ jf0615707

63. Clarisse MD, Lucas EF, Amorim MCV (2000) Avaliação da interação macromolécula/íon $\mathrm{Zn}^{+2}$ em meio aquoso: poli(acrilamida-co-ácido acrílico) e taninos. Polimeros 10:162169. doi:10.1590/S0104-14282000000300013 